\title{
A DIFÍCIL TRAJETÓRIA DOS DIREITOS HUMANOS E A IMPORTÂNCIA DA NORMATIVIDADE NA CONTEMPORANEIDADE
}

\author{
Kleber Ferreira da Silva, Sergio Mastellini \\ Universidade do Oeste Paulista - UNOESTE, Presidente Prudente, SP. E-mail: kfdasi@hotmail.com
}

\section{RESUMO}

O presente estudo tem por escopo examinar a difícil trajetória dos direitos humanos e a importância da normatização na contemporaneidade à luz dos acontecimentos históricos. Os direitos humanos conquistados não são estáticos, nascem de modo gradual e, historicamente caracterizados por lutas sangrentas. Nesse passo, o homem ser social, atribui uma porção de sua liberdade para convívio em sociedade e, deste acordo escolhem aquele que será o depositário e administrador de suas vidas, este com poderes muitas vezes ditatoriais, impõem aos oprimidos um fardo insuportável que acaba em lutas sangrentas. Destas lutas culminou em importantes acontecimentos históricos, destaca-se a Declaração de Independência e Constituição Americana, Declaração do Homem e Cidadão da França, acontecimentos marcantes para história do homem, mas não suficiente para reconhecer sua dignidade, porque o homem continua escravo, sem direitos, sem voz política. O divisor de águas, foi pós Segunda Guerra Mundial, o holocausto, as bombas atômicas jogadas sobre a cidade de Nagasaki e Hiroshima no Japão, a criação da Organização das Nações Unidas e o Tribunal de Nuremberg, levando o ser humano a normatizar direitos universais da humanidade.

Palavras chaves: constituição; humanidade; declaração; guerra mundial; holocausto.

\section{THE DIFFICULT TRAJECTORY OF HUMAN RIGHTS AND THE IMPORTANCE OF NORMATIVITY IN CONTEMPORARYITY.}

\begin{abstract}
ABSTRAT
This study aims to examine the difficult trajectory of human rights and the importance of standardization in contemporary times in light of historical events. The human rights achieved are not static, they are born gradually, and historically characterized by hard fights. So, the man being social, attributes a portion of his freedom to coexist in society and from this agreement they choose the one who will be the trustee and administrator of their lives, and this one with often dictatorial powers, impose an unbearable burden on the oppressed that ends in hard fights. These struggles culminated in important historical events, principally the Declaration of Independence and American Constitution, Declaration of Man and Citizen of France, important events for man's history, but not enough to recognize his dignity, because man remains a slave, without rights, without a political voice. The most importabt, it was post second World War, the holocaust, the atomic bombs dropped on the city of Nagasaki and Hiroshima in Japan, the creation of the United Nations and the Nuremberg Court, leading the human being to standardize universal human rights.

Keywords: constitution; humanity; declaration; world war; holocaust.
\end{abstract}

\section{INTRODUÇÃO}

É pacificado o entendimento que os direitos humanos contemporâneos pari passu aos acontecimentos históricos, neste sentido a doutrina esclarece que no princípio os homens eram independentes, "livres" e isolados na natureza, mas temerosos por sua sobrevivência se viram forçados a sacrificar uma porção de sua 
liberdade; sacrifício colocado sob albergue de leis de sua criação.

É mister dizer que ninguém faz gratuitamente um sacrifício de uma porção de sua liberdade, visando apenas o coletivo, quem sacrifica espera uma contrapartida historicamente percebe pouca simetria nesta contrapartida, corroborando em revoluções, não para romper o contrato, mas para combater a tirania dos administradores - nesse passo, os direitos são históricos, não nascem de uma vez e nem vez por todas, embora sua universalidade pode ser tratada como uma questão cultural, a defesa e dignidade da pessoa humana deve ser posto em prática por todos, em busca de um resultado de entrega deontológica

Nesse sentido o Brasil um dos países fundadores das Nações Unidas, tem como um princípio de fundamento da República a dignidade da pessoa humana, o que diferencia dos demais países capitalistas e socialistas, por reconhecer como fundamentais os direitos civis e políticos, direitos sociais, econômicos e culturais, elevando legislação nacional a um patamar próximo a da "perfeição" no mundo legal.

A ideia é trazer nos capítulos próximos, uma breve história dos direitos humanos em torno de acontecimentos importantes como: Cilindro de Ciro de 539 a.C., Carta Magna de 1215, Petição de Direito 1628, Declaração de Independência Americana 1776, Constituição Americana 1797, Declaração Americana dos Direitos 1791, Declaração do Homem e Cidadão da França 1789, Segunda Guerra Mundial, Organização das Nações Unidas de 1945, o Tribunal de Nuremberg, acontecimentos que influenciaram na Declaração Universal dos Direitos Humanos de 1948 e a importância da Normatividade dos Direitos Humanos contemporâneo.

\section{METODOLOGIA}

O presente artigo realizou-se por meio de pesquisas bibliográficas, legislações e artigos, tendo como objetivo tratar da importância dos direitos humanos e a importância de sua normatização e a aplicação na sociedade em respeito à dignidade da pessoa humana.

\section{RESULTADOS}

Ficou evidenciado que a legislação pátria vigente se mostra em construção, mas próxima da "perfeição" no tocante ao reconhecimento dos Direitos Humanos, no entanto, tão importante, quanto a normatização é pôr em prática, a desigualdade social do país é exacerbada, embora a Constituição Brasileira de 1988 , tenha como princípio balizar a dignidade da pessoa humana, proteção da vida, direitos e garantias, direitos sociais, ainda não conseguiu se ver livre do flagelo da desigualdade, e, não menos importante, um silêncio da sociedade dos crimes contra os nativos.

\section{DISCUSSÃO \\ BREVE HISTÓRIA DOS DIREITOS HUMANOS}

No princípio os homens eram independentes, "livres" e isolados na natureza, cansados de viver com temores e encontrar inimigos a toda parte, e pela incerteza de conservar sua liberdade, se viram forçados a sacrificar uma porção desta, para gozar do restante com mais segurança. (BECCARIA, 2015, p. 23).

O cansaço do homem é compreensível, haja visto que a liberdade a qual se encontravam não era necessariamente uma liberdade, pois a insegurança, o receio de ser escravizado, fustigados por outras pessoas que se aglutinavam em tribos, clãs eram reais. $E$ na busca de proteção se submetem a este sacrifício, porém o problema que surge agora é, a quem atribuir a responsabilidade do depósito destas liberdades, de acordo com Cesare Beccaria (2015) "A soma de todas essas porções de liberdades, sacrificada assim ao bem geral, formou a soberania na nação; e aquele que foi encarregado, pelas leis, do depósito das liberdades e dos cuidados da administração foi proclamando o soberano do povo" (BECCARIA, 2015, p. 23)

Escolhido o responsável - mais forte deixam em sua guarita o depósito de sua liberdade, administração e organização da vida sociedade, com direitos e deveres.

Assim, para compreender esta união e os direitos humanos do homem contemporâneo, é necessário recorrer a investigação histórica, neste Sentido Paulo Nader:

A investigação histórica favorece a compreensão da cultura contemporânea, pois o grande livro da sabedoria foi escrito ao longo dos séculos, [...] como anota Del Vecchio, “(...) o presente, sem o passado, carece de sentido; e o passado revive no 
presente". (NADER, 2018, p. 133)

Sem investigação histórica da cultura humana, de seu passado, não encontraremos resposta para conjectura presente dos direitos humanos - a história não pode ser tratada como um baú velho, onde guarda-se os itens sem valores, porque apenas no passado é encontrado fagulha inicial, o que se compreende mormente como direitos humanos - são conquistas findadas em constantes lutas, conquistas com suor de sangue dos antepassados, em cada época da história humana, os direitos humanos encontrarse-á fragmentos, porque, nascem de modo gradual, não todos de uma vez, e, nem de uma vez por todas (BOBBIO, 2004, p. 8).

Nesse passo, historiadores atribuem ao Cilindro de Ciro, documento encomendado pelo Rei da Pérsia, Ciro II, o conquistador da Babilônia 539. a.C, como sendo um dos primeiros documentos a reconhecer direitos humanos, libertando escravos, instituindo igualdade racial, direito à escolha da sua própria religião. (UDH, 2008).

Importante registro também se encontra em 1215, quando o Rei João da Grã-Bretanha, viola inúmeras leis e costumes, revoltando os súditos, que forçam o monarca assinar a Carta Magna, garantindo que a coroa não mais interfira, sobre o direito de propriedade, religião, e que estabeleça a garantia do devido processo e igualdade perante a lei. (UDH, 2008).

Em 1628 outro elogiável acontecimento histórico, a Petição de Direito de 1628, GrãBretanha, onde o parlamento impõe freios e contrapesos na administração do Rei Carlos I uma espécie separação de poder - impedindo o rei de instituir qualquer espécie de tributo, sem o consentimento do parlamento, de prender ou mandar prender alguém sem motivo, proibindo autorizar o aquartelado dos soldados nas casas dos cidadãos, e que lei marcial não poderia ser usada em tempo de paz. (UDH, 2008).

A partir do século XVIII, uma sequência de importantes acontecimentos para humanidade no que tange a conquistas de direitos no ocidente, em 1776 a aprovação da declaração de independência dos Estados Unidos da Grã-Bretanha, acentuada sob dois grandes pilares, direitos individuais e de revolução em 1787 a Constituição Americana, e em 1791 a Declaração dos Direitos dos Estados Unidos. (UDH, 2008).
Dentre todos estes acontecimentos históricos, a Constituição Americana século XVIII, foi um importante marco, muito embora não tenha assegurado igualdade a todos americanos, visto a manutenção da escravidão até segunda metade do século XX. (CASADO FILHO, 2012, p. 36).

No continente europeu, especificamente na França, a insatisfação dos franceses em 1789 leva a grande Revolução, cujo lema se prolonga até nos dias atuais "Liberté, Egalité, Fraternité", desta sangrenta luta surge a talvez o mais importante acontecimento em torno de conquistas de direitos - a Declaração dos Direitos do Homem e do Cidadão, abolindo monarquia e estabelecendo a primeira República - é considerada a primeira grande declaração dos direitos do homem, que influencia na declaração dos direitos humanos. (UDH, 2008).

Neste sentido, de acordo com Pedro Lenza (2021, p. 1160) a Revolução Francesa, partindo dos lemas liberdade, igualdade e fraternidade, anunciam um impulso nos direitos humanos, por meio de uma evolução reacionária, que seriam transladados em direitos fundamentais de $1^{\text {a }}$ geração ou dimensão, $2^{a}$ geração ou dimensão e de 3 a geração. Os direitos de 1a geração ou dimensão, impulsionam a mudança da característica estatal, de um Estado autoritário, opressor, para um Estado de direito, reconhecendo os direitos civis e políticos dos indivíduos traduzidos em liberdade. (LENZA, 2021, p. 1160).

Em relação aos direitos humanos de 2 a geração ou dimensão, é impulsionado pelas lutas dos operários Ingleses e Franceses 1848, visto as péssimas condições de trabalhos, originado a chamada Revolução Industrial Europeia - assim evidenciando a necessidade da tutela estatal, para que fosse resguardado o mínimo de direitos aos indivíduos, seja sociais, culturais, econômicos e até mesmo direitos coletivos, vista a situação da relação de hipossuficiência dos operários, frente aos industriais detentores do capital, assim nascem os direitos fundamentais de segunda geração ou dimensão, não mais com abstenção do Estado, mas uma interferência positiva, assim correspondendo aos direitos de igualdade.(LENZA, 2021, p. 1161)

Os direitos de 3a geração ou dimensão, são marcados pelas preocupações globais, como a preservação ambiental, a proteção da humanidade, ou seja, direitos transindividuais, proteção do gênero humano, como direito ao 
desenvolvimento, à paz, à comunicação etc. proteções dotadas de altíssimo teor de humanismo e universalidade, inserido num contexto de uma coletividade de direitos de solidariedade ou fraternidade. (LENZA, 2021, p. 1161)

Os direitos de 1á, 2a e 3a geração ou dimensão são catalisadores para o surgimento de novos direitos, seja, de quarta, quinta, sexta dimensão etc. Outro ponto importante dos direitos humanos é sua universalidade, indelegabilidade, intransferível, transcende áreas geográficas, independentemente da formalidade ou consentimento de determinada nação - muito embora ressalta a importância da internalização pelo Estado soberano, como reconhecimento de direitos fundamentais, e asseguramento de seu cumprimento por meio de instrumentos garantidores, para impedir opressão por parte do Estado ou mesmo cidadãos de tolher direitos uns dos outros.

Nesse passo, para o Vice-ProcuradorGeral do Trabalho Jeferson Luiz Pereira, (2009) a Revolução Francesa, foi um dos primeiros passos da conquista da cidadania.

[...] É com a Revolução Francesa (1789), quando se produz um salto de gigante talvez o primeiro passo na larga corrida de liberação da marca de súdito na conquista desta condição, que a palavra cidadão se populariza e passa a expressar um ideal de vida compartilhada. (PEREIRA, 2009, 147)

Realmente a Revolução Francesa, foi um impulso na alforria das pessoas em relação ao Estado, popularizando um ideal de ser humano, com direitos a sua dignidade e sobrevivência, não se subsumindo a marca de súdito, mas sim um ideal de vida, ser humano com uma face, mas será se tais acontecimentos alcançaria a todo?

Neste sentido, Napoleão Casado Filho (2012, p. 39), Constituição Americana trata que todos os homens nascem "livres", se são "livres" porque manteve a escravidão; a Declaração Francesa, todos os homens nascem e permanecem "livres" e iguais em direito, se são iguais em direitos, porque o voto censitário, é inegável que tais acontecimentos são importantes, o problema é que nem todos alcança, pois de um lado jorra leite e mel, de outro um deserto que espelha um rio inalcançável. Assim, para o que conhecemos hodiernamente como direitos humanos, viesse a se debater ocorre apenas a funesta Segunda Guerra Mundial.

A Segunda Guerra, foi muito em consequência da primeira grande guerra - os Alemães sucumbiram, se sentiram humilhados e obrigados a assinar um tratado de paz, foi imposto ainda aos Alemães perdas significativas de território e riquezas antes conquistadas, também foram obrigados a pagar vultosas indenizações que levam a um colapso de sua moeda e consequente aumento de desemprego. (MAIOLI, 2004, p. 2).

Com o cenário armado, entra em cena Adolf Hitler pregando a grandeza nacional e superioridade racial ariana - para ele apenas está deveria florescer como raça mais avançada, para Harari (2015, p. 131) a principal ambição dos nazistas era:

[...] proteger a
humanidade da
degeneração e encorajar
sua evolução progressiva
[...] os nazistas afirmavam
que a raça ariana, a forma
mais avançada de
humanidade, tinha de ser
protegida e encorajada, ao
passo que tipos
degenerados de Homo
sapiens, como judeus,
ciganos, homossexuais e
doentes mentais, tinham
de ser colocados em
quarentena e até mesmo
exterminados [...] Se lhes
fosse permitido procriar -
e, em particular, procriar
com arianos -, eles
adulterariam todas as
populações humanas e
condenariam o Homo
sapiens à extinção.
(HARARI, 2015, p. 131)

Para realizar suas convicções os nazistas não se importava quais meios se valeriam, mas sim "purificar" a raça humana - exterminar se fosse necessário, para que raças "inferiores" não procriassem em particular como os arianos, pensamento que levou ao extermínio de muitos judeus, negros, homossexual etc.

Com o fim da Guerra, os pensamentos nazistas não floresceram, mas abriram a mente 
das grandes nações que tais acontecimentos, não poderiam ser toleradas e não poderia mais acontecer, para isso em 1945, acordam pela necessidade de criar uma entidade neutra, com status de Estado e finalidade de proteger, promover a paz e salvar as gerações futuras, a Organização das Nações Unidas. (CASADO FILHO, 2012, p. 43).

Pari passu, surge outro problema após a guerra, o que fazer com os prisioneiros, executálos sem julgamento? Para os Americanos apesar das barbáries realizadas pelos nazistas, mereciam um julgamento, pensamento contrários aos da França e União Soviética - o pensamento Americano passa a ser vitorioso com apoio da Inglaterra, chegando assim ao consenso para atribuir aos nazistas um julgamento "justo" e civilizado por um Tribunal, para que não se igualassem aos nazistas, que simplesmente executavam seus prisioneiros de guerra. (ARAGÃO, 2009, p. 84). Nesse passo, o tribunal foi instalado em Nuremberg, local onde o terceiro reich realizava seus comícios e passeatas de propagandas nazistas.

\section{O TRIBUNAL DE NUREMBERG}

Sobrevindo a Segunda Guerra Mundial as nações vencedoras começaram a repensar uma política de punição aos criminosos de guerra, de acordo com Napoleão Casado Filho.

Tais abusos impactaram o mundo de tal forma que uma resposta à humanidade era essencial. Não era possível ficar estático. Os Aliados, vencedores do conflito, providenciaram $\quad 0$ julgamento dos nazistas em Nuremberg [...] Tribunais militares, que sofreram diversas críticas no mundo jurídico [...]. (CASADO FILHO, 2012, p. 42)

Evidente que as atrocidades dos nazistas, mereciam uma resposta, não somente pelos atos cometidos, mas para mostrar a futuros agressores, que a humanidade não toleraria mais que isso voltasse a acontecer, é certo, que a história tacha o tribunal de Nuremberg, como exceção, mas que resposta poderia ser dada naquele momento tão conturbado?
De acordo com Eugênio José Guilherme Aragão (2009, p.84) Winston Churchill foi o divisor de águas para instalação do tribunal, porque foi contrário a posição da França e da União Soviética, que queriam apenas fuzilar os prisioneiros de guerra - Churchill passa a concordar com o presidente Americano Roosevelt, que os prisioneiros precisavam ser punidos, mas de modo civilizado, aplicando justiça - mesmo que os nazistas não tinham garantido aos seus prisioneiros, fazendo assim, desta ideia o surgimento da Justiça Penal Internacional, para crimes de Guerra.

Fatos estes reproduzidos fielmente pelo filme Julgamento de Nuremberg (CONNERS, 2020), julgamento que marcaria a história, no entanto, o problema em torno do julgamento, foi que apenas serviu para cumprir formalidades, a condenação e a pena já era certa, neste sentido Napoleão Casado Filho.

[...]os Tribunais foram criados especificamente para [...] que os julgadores se sentissem pressionados a condenar os réus, de forma a justificar sua convocação. Inocentar todos seria atestar que a convocação e a formação do Tribunal eram desnecessárias. (Casado Filho, 2012, p. 137)

É notório que quando criando um tribunal de exceção, tende os julgadores a rigor impor as mais severas penas aos acusados, e, cabendo a estes provar que não é culpado - para que isso não ocorra na nação pátria, Pedro Lenza (2021, p. 1253) diz que a Constituição Brasileira de 1988, (BRASIL, 1988), proíbe expressamente designar ou criar, seja por deliberação legislativa ou outra, tribunal de exceção para julgar através de processo, determinado caso, tenha ocorrido ou não.

Mesmo que encontre justificação para criação de um tribunal de exceção, e que se argumente que este será fundado na publicidade, contraditório e ampla defesa, não justifica sua criação, pois agrediria a Lex. magna Brasileira. Mas tais justificações foram basilares para o julgamento dos nazistas; de acordo com Tatiane Fonseca da Silva (2014, p. 56), foi dado publicidade em 18 de outubro de 1945, por meio do Estatuto do Tribunal Militar Internacional estabelecidos as regras do processo, do 
julgamento e as acusações nas seguintes modalidades.

[...]acusações [...] podem ser classificadas em quatro modalidades principais: 1 ) Conspiração e atos deliberados de agressão, que significa a execução de planos destinados a tomar o poder e instituir um regime totalitário; 2) Crimes de guerra, que consiste nas infrações aos costumes e leis de guerra, na prática de maus-tratos, homicídios, trabalhos forçados etc.; 3) Crimes contra a paz, que são os que se referem a administrar, preparar, incitar e dar continuidade à guerra; 4) Crimes contra a humanidade, que são os homicídios em massa, extermínios,

escravizações,

deportações e todo e qualquer outro ato desumano ou cruel contra civis. (SILVA, 2014, p. 56)

Após o estabelecimento das acusações, inicia o julgamento em 20 de novembro de 1945 - sendo o dirigente de acusação o ProcuradorGeral Norte-Americano Robert H. Jackson presidência do tribunal era composta por juízes das potências afetada pela guerra, levantando dúvida se o julgamento seria justo, como publicitava o Presidente Americano e o PrimeiroMinistro Inglês, haja visto a limitação da defesa dos réus (CONNERS, 2020).

$E$, por quase um ano de julgamento, a sentença foi publicada em 30 de setembro de 1946, estabelecendo as sanções, da seguinte maneira, como expôs Luiz Olavo Baptista.

A sentença do Tribunal foi publicada em 30 de setembro de 1946 [...] pena de morte 12 dos acusados: Göring, Ribbentrop, Keitel, Kaltenbrunner, Rosenberg, Frank, Frick, Streicher, Sauckel, Jodl, SeyssInquart e Bormann. Três [...] à prisão perpétua: Hess, Funk e o almirante
Raeder. [...] quatro [...] penas de dez a vinte anos de prisão: Dönitz, Schirach, Speer e Neurath. [...] o Tribunal absolveu três dos acusados: Hjalmar Schacht, Franz von Papen e Hans Fritzsche. (BAPTISTA, 2018, p. 26)

O destaque do julgamento, se dá em torno daqueles que não foram executados, sendo três condenados à prisão perpétua, quatro a penas entre dez e vinte anos, e para dar o ar de um julgamento justo, três foram absolvidos de todas as acusações.

Muito embora o tribunal tenha sofridos inúmeras críticas do mundo jurídico, por sua composição e suposta maquiagem de um julgamento justo, o Tribunal de Nuremberg, deu grande contribuição de acordo com Napoleão Casado Filho $(2012$, p. 136) na criação de outro tribunal, com objetivo de julgar crimes cometidos contra humanidade, o Tribunal Penal Internacional-TPI em 1998, acrescenta Casado Filho que este tribunal é uma.

[...] Corte Internacional, independente,

permanente, destinada a julgar os crimes mais graves conhecidos pelo homem, especificamente o crime de genocídio, crimes de guerra e crimes contra a humanidade (2012, p.137) [...] lamentável [...] é a ausência dos Estados Unidos da América, que não ratificaram o Estatuto de Roma e se consideram desobrigados de todos os ônus dele decorrentes. $\mathrm{O}$ Brasil, no entanto, ratificou o Estatuto em 20 de junho de 2002 e, em 2004, com a Emenda Constitucional n. 45, passou a ter previsão constitucional de Tribunais Internacionais como o TPI. (CASADO FILHO, 2012, p. 138).

Como bem menciona Casado Filho, é realmente lamentável a ausência da maior 
potência mundial, nação singular no Tribunal Penal Internacional.

De uma forma ou de outra, o Tribunal de Nuremberg, apesar de imperfeições abriu a possibilidade da discussão entre as nações, desta por meios de acordos celebram a criação de um Tribunal Internacional Penal para julgar e estabelecer sanções a crime de genocídio, de guerra, contra a humanidade, bem como, para contribuição da mais importante Constituição de Direitos Humanos a Declaração Universal dos Direitos Humanos de 1948.

\section{A DECLARAÇÃO UNIVERSAL DOS DIREITOS HUMANOS DE 1948}

Cabe rememorar, antes da declaração dos Direitos Humanos de 1948, outras declarações e acontecimentos históricos contribuíram em sua elaboração, como a Carta Magna 1215 a Petição de Direito 1628 da Inglaterra; Declaração de Independência 1776, a Constituição 1787 e Declaração de Direitos 1791 Americana, e a Declaração dos Direitos do Homem e do cidadão 1789 da França, destaca-se ainda contribuições de filósofos socialistas, como Karl Marx, que de acordo com Napoleão Casado Filho (p .40, 2012) incita os trabalhadores a se unirem e lutar contra seus exploradores, o que se traduziu em direitos.

A Declaração Universal dos Direitos Humanos das Nações Unidas, é a primeira grande declaração universal dos direitos da humanidade, visto que as declarações antecedentes estavam ligadas a determinada sociedade geograficamente. A declaração consagra nos seus trintas artigos a liberdade, a proteção contra o império da lei, a igualdade sem distinção de raça, cor, credo, religião, direito a um julgamento justo e garantia da ampla defesa, direito a nacionalidade, com alicerce na dignidade da pessoa humana, nesse passo, se tornando a Carta Magna Internacional dos direitos da Humanidade. (ONU, 1945)

No entanto, para alguns doutrinadores essa universalidade, não tem aplicação em sentido lato sensu, para Boaventura Souza Santos (2018, p. 112), os direitos humanos não são universais na sua aplicação, estão presente em quatros regimes internacionais, o europeu, o interamericano, o africano e o asiático, acrescenta Santos (2018, p. 113), que a universalidade é uma questão cultural do ocidente, logo, são universais apenas quando olhado no ponto de vista ocidental.
Por outro lado, Boaventura Souza Santos, afirma que:

A luta pelos direitos
humanos e, em geral, pela
defesa e promoção da
dignidade humana não é
um mero exercício
intelectual, é uma prática
que resulta de uma
entrega moral, afetiva e
emocional ancorada na
incondicionalidade do
inconformismo e da
exigência de ação.
(SANTOS, 2018, p. 117)

No entendimento do ilustre mestre Boaventura Souza Santos, a luta dos direitos humanos não pode ser um mero exercício intelectual, formal, de palavras que emocionantes seu ouvinte, deve atacar, cuidar das feridas do doente; criar remédios eficazes, transcender o aspecto formal, cujo resultado material se amolda numa entrega moral, afetiva e emocional, impulsionada incessantemente por ações engajadas por toda a sociedade.

Embora, os direitos humanos não sejam considerados em sentido lato sensu, devido ao choque de cultura, seja do Oriente ou do Ocidente, há que se considerar que o alicerce fundamental da Declaração Universal dos Direitos Humanos, é sem dúvida a dignidade da pessoa humana, qualidade intrínseca dos seres humanos, que transcende a lei escrita, não quer dizer que o aspecto formal não seja importante, é sim, porque se o Estado internalizar em sua legislação, alargar mecanismos que visam coibir violações de terceiros ou mesmo sua, veremos no tópico seguinte a importância da normatização e direitos humanos na contemporaneidade.

\section{NORMATIVIDADE E DIREITOS HUMANOS NA CONTEMPORANEIDADE}

A normatização é um passo importante, mas não é suficiente, porque os direitos humanos vão além transcendem a positivação, a positivação deve ser em sentido de declaratório, mas também, deve garantir mecanismos assecuratório - na medida que limita o poder estatal e o estabelecimento de igualdade entre os indivíduos. (CASADO FILHO, 2012, p. 21).

A positivação não é garantia que os direitos não serão violados, pode o próprio Estado violá-los, como a prisão arbitrária, mas é a garantia da existência de meios necessários para 
combater a repressão, a ilegalidade ou abuso de poder do Estado ou de terceiros, por exemplo, Habeas Corpus, Mandado de Segurança, Habeas Data, remédios constitucionais, encontrados na Carta Magna Brasileira.

O Brasil como um dos países fundadores das Nações Unidas, não seria indiferente a da Declaração dos direitos humanos, tanto que tem como um princípio de fundamento da República, como nos ensina Sérgio Cavalieri Filho (2015, p.53) "[...] dignidade da pessoa humana, [...] um dos fundamentos da. República Federativa do Brasil (art. $1^{\circ}$, III)".

Nesse passo, associado a dignidade da pessoa humana, encontramos também na $\mathrm{CF} / 88$ artigo 5으, os direitos e garantias individuais; os coletivos; à vida; privacidade; igualdade; liberdade; devido processo legal; contraditório; ampla defesa; liberdade de expressão; bem como os assecuratórios, remédios contra arbitrariedades, como habeas corpus; mandado de segurança; mandado de injunção; habeas datas etc.

Não tão menos importante, encontramos também no artigo 6으 da Carta Magna Brasileira de 1988, referência aos direitos sociais, como o de educação; saúde; alimentação; trabalho; moradia; transporte etc.

Os ilustrados artigos da Lex Carta Brasileira, tem precípuo objetivo, garantir aos nacionais irrestritamente, e aos não nacionais ressalvados os exclusivos dos nacionais, mas sempre com objetivo da preservação da plenitude da dignidade humana, o que torna o Brasil não perfeito, mas um país diferenciado em relação aos demais países signatários das Nações Unidas, neste sentido Napoleão Casado Filho.

Os países ocidentais [...] direitos civis e políticos eram autoaplicáveis, [...] sociais, econômicos e culturais [...] "programáticos" [...] socialistas [...] finalidade maior do Estado era promover a igualdade entre os cidadãos, mesmo que para isso [...] privá-los [...] Direitos Civis e Políticos. (2012, p.70). O Brasil, após a redemocratização [...] 1988, já não acreditava na Divisão do mundo em capitalistas e socialistas e, em 24-1-1992, ratifica o Pacto Internacional dos Direitos Econômicos, Sociais e Culturais. (2012,p.71). [...] No Brasil, ambos podem ser considerados [...] direitos fundamentais, e os cidadãos têm a sua disposição todos os meios processuais para assegurar sua proteção. (CASADO FILHO, 2012, p. 107).

Neste sentido o Brasil se diferencia dos países capitalistas e socialistas, ao reconhecer como fundamentais tanto os direitos civis e políticos e, os direitos sociais, econômicos e culturais, elevando legislação pátria num patamar de "perfeição" no mundo legal; por outro lado como nem tudo são flores, os espinhos ou problema assim dizendo, é de colocar na pratica, campo material - em especial no combate à pobreza - mazela mundial, que ceifa mais vidas que muitas guerras, de acordo com Flávia Piovesan.

Para a Organização
Mundial de Saúde, a
pobreza, pasmem, acima
de qualquer guerra, da
somatória das guerras, é a
principal causa mortis do
mundo. Por dia há 50 mil
vidas desperdiçadas no
mundo, sendo 34 mil de
crianças menores de 5
anos. (PIOVESAN, 2009, p.
110).

São estarrecedores, que faz questionar se a declaração Universal dos Direitos Humanos, realmente trouxe dignidade à raça humana, como aceitar outro ser humano morrer de fome pior crianças, que sequer tiveram a chance de andar, brincar, ter uma infância, a esperança de serem felizes.

A desigualdade social, é um genocídio silencioso, porque as pessoas não se interessam pelo tema ou acreditam que a responsabilidade é toda do Estado. O Brasil embora um dos pais mais rico do mundo e, com uma enormidades de diversidades naturais, tem uma desigualdade exacerbada, muito em relação a corrupção, violência, tráfico de entorpecentes - Flávia Piovesan (2009, p. 110) o Brasil é uma das maiores economias do mundo, entre o nono e 
décimo lugar, por outro lado, é quarto mais desigual e violento.

Outra mazela presente de nossa sociedade, está ligado a outro genocídio silencioso, os dos nativos, neste sentido Chistian Ramos Veloz (2009, p. 124) a Declaração Universal de Direitos Humanos, tinha e tem como objetivo impedir que ocorra novos crimes contra a da humanidade como ocorreu na Segunda Guerra Mundial, mas não pensou em combater outro, o contra os povos indígenas. Inobservância corrigida (2009, p. 125) apenas com a Convenção 169 da Organização internacional do Trabalho de 1989, e sendo reconhecida pelo Brasil apenas em 2004, via Decreto 5.051/2004, porque antes de 2004, falar nesta convecção, seria atentar contra a soberania do país.

$\mathrm{O}$ que se mostrou inverídico, visto que, o reconhecimento dos direitos dos povos indígenas e tribos, é sobre o uso da a terra, do trabalho, de sua identidade, língua, costumes, cabendo aos Estados onde estes nativos estão estabelecidos a criação de condições de igualdade e de direitos, oportunidades e não transferência de soberania do território.

A normatização dos direitos seja, sociais, econômicos, de proteção à dignidade da pessoa humana, é importantíssima, porque caso ocorra alguma violação, em detrimento do polo hipossuficiente, este poderá se valer de direitos assecuratórios na garantia da plena da proteção nos termos da lei.

\section{CONSIDERAÇÕES}

Para se chegar ao homem da contemporaneidade é necessário conhecer a história do homem do passado, como foram, o que fizeram, o que não repetir no presente e o que impedir que ocorra no futuro.

Foram tortuosos os trajetos percorridos pela humanidade, até a Declaração Universal dos Direitos Humanos de 1948, nestes caminhos foram ceifadas muitas vidas, seja, na Revolução Francesa que rompe com a monarquia e estabelecendo a primeira república, partindo dos lemas liberdade, igualdade e fraternidade, anunciam um impulso nos direitos humanos, transladados em direitos fundamentais de 1a dimensão, 2a dimensão e de $3 \underline{a}$ dimensão reprimidos pela Segunda Guerra Mundial, iniciada pelos nazistas - holocausto de Judeus - e finalizada com os Americanos jogando a bomba atômica sobre as cidades de Hiroshima e Nagasaki no Japão - maior arma destrutiva, elaborada e utilizada pelo homem até então; nesse passo, a historicidade mostra que os direitos foram conquistados por lutas sangrentas, - que não se deveria mais admitir hodiernamente.

Assim pode-se dizer que, a última grande luta da humanidade por suor de sangue, foi a Segunda Guerra Mundial, que colocou em risco a existência da vida e do planeta, desta funesta guerra erigiu uma entidade mediadora com status de Estado e neutra, a Organização das Nações Unidas, com objetivo de proteger, promover a paz e salvar as gerações futuras.

A criação das Nações Unidas e do Tribunal de Nuremberg, foram acontecimentos importantes pós Guerra, no uma maior importante deve ser atribuída a Declaração Universal dos Direitos Humanos 1948, reconhecida como a Carta Magna Internacional dos Direitos Humanos, que consagra em trintas artigos, a liberdade, a proteção contra o império da lei, a igualdade sem distinção de raça, cor, credo, religião, direito a julgamento justo, garantia de defesa, direito a nacionalidade, todos alicerçados na dignidade da pessoa humana.

$\mathrm{Na}$ visão de doutrinadores como Boaventura Souza Santos, Napoleão Casado Filho, a universalidade da declaração, não tem aplicação em sentido latu sensu, em decorrência da diferentes culturas e posicionamentos políticos; os Estados Capitalistas entendem que os direitos civis e políticos são autoaplicáveis, os sociais, econômicos são programáticos; os Socialistas entendem que é obrigação do Estado promover a igualdade, mesmo que prive alguns direitos civis e políticos; em contraposição aos dois, temos uma terceira visão mais moderna, que é a do Estado Brasileiro, que reconhece como fundamentais tanto os direitos civis e políticos, sociais, econômicos e culturais. Nesse passo a Constituição Brasileira de 1988, tem em seus princípios fundadores a dignidade humana, a proteção da vida, direitos e garantias, direitos sociais, entretanto, ainda não conseguiu se ver livre do flagelo da desigualdade, e, não menos importante, a falta de proteção dos povos nativos.

Por fim, os direitos humanos, são caracterizados historicamente por lutas, assemelha-se a uma semente, demora a germinar porque a terra é árida, e para crescer, florir é necessário persistência, ser vigilante com os já existentes e fortalecê-los com novos. 


\section{REFERÊNCIAS.}

ARAGÃO, Eugenio Jose Guilherme. Crimes Contra a Humanidade: Sistema Internacional de Repressão. Revista do Tribunal Superior do Trabalho, Rio de Janeiro, v.75, n. 1, jan./mar., $2009 . \quad$ Disponível em https://hdl.handle.net/20.500.12178/6558.

Acesso em: 06 out. 2020.

BAPTISTA, Luiz Olavo. Os grandes julgamentos da história. 1. ed. Rio de Janeiro: Nova Fronteira, 2018.

BECCARIA, Cesare. Dos delitos e das penas. São Paulo, Edipro, 2015.

BOBBIO, Norberto. A era dos direitos. Rio de Janeiro: Elsevier, 2004.

BRASIL. Constituição (1988). Constituição da República Federativa do Brasil. Brasília: Senado Federal, $1988 . \quad$ Disponível em: http://www.planalto.gov.br/ccivil 03/constituica o/constituicaocompilado.htm. Acesso em: 14 out. 2020.

CASADO FILHO, Napoleão. Direitos humanos e fundamentais. São Paulo: Saraiva, 2012.

CAVALIERI FILHO, Sergio. Programa de Sociologia Jurídica. 14 ed. Rio de Janeiro: Forense, 2015.

CONNERS, Leahy Ross. Tribunal de Nuremberg. 0 Julgamento de Nuremberg resumo 60. 2020. Disponível em: https://www.youtube.com/watch?v=rLggJ5dFsm k\&feature=youtu.be. Acesso em: 05 out. 2020.

LENZA, Pedro. Direito Constitucional. 25. ed. São Paulo: Saraiva, 2021.

HARARI, Yuval Noah. Uma breve história da humanidade. Tradução Janaina Marcoantonio 1. ed. Porto Alegre, RS: L\&PM, 2015.

MAIOLI, Ivo A. História da Segunda Guerra Mundial. Compilação e Pesquisa, 2004.

NADER, Paulo. Filosofia do direito. 25. ed. Rio de Janeiro: Forense, 2018.

ONU. Organização das Nações Unidas. Declaração Universal do Direitos Humanos. $1945 . \quad$ Disponível em: https://www.un.org/en/universal-declarationhuman-rights/index.html. Acesso em: 13 out. $2020 . \quad$ https://doi.org/10.11606/issn.23169125.v0i3p13-17

PEREIRA, Jeferson Luiz. Discurso do Exmo. Sr. Vice-Procurador-Geral do Trabalho em homenagem à nova administração do TST. Revista do Tribunal Superior do Trabalho, Rio de Janeiro, v. 75, n. 1, jan./mar., 2009. Disponível em https://hdl.handle.net/20.500.12178/6558. Acesso em: 06 out. 2020.

PIOVESAN, Flavia. Direitos humanos: Desafios e perspectivas contemporâneas. Revista do Tribunal Superior do Trabalho, Rio de Janeiro, v. 75 , n. 1, jan./mar., 2009. Disponível em https://hdl.handle.net/20.500.12178/6558.

Acesso em: 06 out. 2020.

SILVA, Tatiane Fonseca. O Julgamento de Nuremberg e sua relação com os direitos fundamentais e com o direito internacional: Uma análise necessária. Revista do Laboratório de Estudo da Violência da Unesp, Marília, v. 13, maio, 2014. Disponível em: https://revistas.marilia.unesp.br/index.php/levs/ article/view/3746/0. Acesso em: 18 out. 2020.

SANTOS, Boaventura Souza. Construindo as Epistemologias do Sul: antologia essencial: para um pensamento alternativo de alternativas. 1. ed. Ciudad Autónoma de Buenos Aires: CLACSO, 2018. v. II

UDH. Unidos pelos Direitos Humanos. Uma Breve História dos Direitos Humanos. 2008. Disponível em:

https://www.unidosparaosdireitoshumanos.com. pt/what-are-human-rights/briefhistory/\#: :text=0s\%20decretos\%20que\%20Ciro \%20fez,conquistaram\%20a\%20cidade\%20da\%20 Babil\%C3\%B3nia. Acesso em: 10 out. 2020.

VELOZ, Chistian Ramos. Trabalho Indígena. Revista do Tribunal Superior do Trabalho, Rio de Janeiro, v. 75, n. 1, jan./mar., 2009. Disponível em https://hdl.handle.net/20.500.12178/6558. Acesso em: 06 out. 2020. 